\title{
Demographic parameters of southern right whales off South Africa
}

\author{
Peter B. Best* ${ }^{*}$ Anabela Brandẽo ${ }^{+}$and Doug S. Butterworth ${ }^{+}$
}

Contacte-mail: pbest@samuseum.ac.za

\begin{abstract}
Aerial counts of right whale cow-calf pairs on the south coast of South Africa between 1971 and 1998 indicate an annual instantaneous population increase rate of 0.068 per year $(\mathrm{SE}=0.004)$ over this period. Annual photographic surveys since 1979 have resulted in 901 resightings of 550 individual cows. Observed calving intervals ranged from 2-15 years, with a principal mode at 3 years and secondary modes at 6, 9 and 12 years, but these make no allowance for missed calvings. Using the model of Payne et al. (1990), a maximum calving interval of 5 years produces the best fit to the data giving a mean calving interval of 3.12 years (95\% confidence interval: 3.07 , 3.17). The same model produces an estimate for adult female survival rate of 0.983 (95\% CI: 0.972, 0.994). The Payne et al. (1990) model is extended to incorporate information on the observed ages of first reproduction of grey-blazed calves, which are known to be female. This allows the estimation of age at first parturition (median 7.88 years 95\% CI 7.17, 9.29). Updates of estimates and confidence intervals for the other demographic parameters are: adult female survival rate $0.986(0.976,0.999)$; first year survival rate $0.913(0.601,0.994)$ and instantaneous population increase rate $0.071(0.059,0.082)$. These biological parameter estimates are shown to be compatible with the observed increase rate of the population without the need to postulate immigration.
\end{abstract}

KEYWORDS: RIGHT WHALE; SOUTHERN HEMISPHERE; POPULATION PARAMETERS; SURVIVORSHIP; REPRODUCTION; MATURATION; SURVEY-AERIAL; TRENDS; MODELLING

\section{INTRODUCTION}

Counts made on fixed-wing aerial surveys of the population of right whales (Eubalaena australis) that over-winters on the southern coast of South Africa indicate an instantaneous increase rate of 0.068 per year between 1971 and 1987 (Best, 1990b). Butterworth and Best (1990) have shown that this rate of increase is compatible only with a relatively restricted range of values for calving rate, age at first parturition and survival rate. Between 1979 and 1998, aerial photographs of right whales have been taken annually on separate helicopter surveys, and used for photo-identification of individuals from their callosity patterns and/or dorsal pigmentation (Best, 1990a). In this paper, the results of the photo-identification project are analysed to provide estimates of calving interval, survival rate and age at first parturition, and to investigate their compatibility with the observed rate of population increase in the context of Butterworth and Best's (1990) results.

\section{MATERIAL AND METHODS}

Between 1969 and 1987, fixed-wing surveys were flown off the south coast of South Africa from Woody Cape, Algoa Bay, to Muizenberg, False Bay, in late September/early October each year, and counts of all right whales seen were made. The techniques used and results obtained have already been published (Best, 1990b). From 1979 to 1998, annual photographic surveys of the right whale population on the southern coast of South Africa have been carried out by helicopter. Details of the survey techniques have already been published (Best, 1990a), but in the context of this paper the important point is that the surveys were carried out in as standard a manner as possible. To this end they were flown at the same time of year each year (earliest flight 6 October, latest flight 25 October, with $77 \%$ of animals being photographed between 11 and 21 October), using the same strategy on each flight. The same stretch of coastline, Nature's Valley to Muizenberg, was searched once each year, usually from east to west so that the pilot and photographer were on the coastward side of the aircraft. Where possible, flights were confined to days of good visibility and when surface winds were less than 15 knots. Searching was undertaken at a height of $1,000 \mathrm{ft}(305 \mathrm{~m})$; any whale encountered was inspected for the presence of a calf, and if one was detected, the aircraft would descend to $300 \mathrm{ft}$ (95m) for photography. Unless supplies were running low, usually one film (12 exposures) was taken of each cow-calf pair. Animals without calves were normally not photographed.

For all animals except calves, the photographs from each year's survey were compared with the existing catalogue of known individuals. Each animal was compared in turn with the entire catalogue, and potential matches noted. The original photographs of any potential matches were then compared with those of the survey animal. If a match was established, the animal was incorporated in the catalogue as a 'synonym'. If no match was found, photographs of the survey animal were then compared again with the entire catalogue before it was accepted as a new individual. In total, 1,451 cow-calf pairs were photographed between 1979 and 1998 , with a final catalogue of 550 individual cows. Intervals between calves were established on 901 occasions.

\section{Calving interval and survival rates}

Observed calving intervals are biased representations of the true calving frequency, because inter alia cows on longer intervals are under-represented in the sample (having a greater proportion of incomplete calving intervals) and no allowance is made for missed calvings. In reality, a cow

\footnotetext{
* Mammal Research Institute, University of Pretoria, Pretoria 0002, South Africa (mailing address: c/o South African Museum, Box 61, Cape Town 8000 , South Africa).

${ }^{+}$Marine Resource Assessment and Management Group (MARAM), Department of Mathematics and Applied Mathematics, University of Cape Town, Rondebosch 7701, South Africa.
} 
calving in a particular year might not be photographed because (a) the calf died before the survey, or was born after the survey, or (b) the cow plus calf were outside the survey area at the time of the survey, or were in the survey area but were overflown. To estimate the true calving interval, the maximum likelihood approach adopted in Payne et al. (1990) and developed further by Cooke et al. (1993) has been used. Their models are summarised below, mainly because some of the equations involved were printed incorrectly in Payne et al. (1990). For a more detailed discussion of these models the reader is referred to the above references.

The same notation as Payne et al. (1990) is adopted:

$p_{j} \quad$ the probability that a calving in year $j$ is recorded;

$h_{j} \quad$ probability that a female calving in year $m$ has her next calf in year $m+j$, given that she has survived to year $m+j$;

$q_{j} \quad$ the probability that a female calving in year $m$ has a calf in year $m+j$, given that she has survived to year $m+j$

$n_{i} \quad$ number of calvings recorded in year $i$;

$n_{i j} \quad$ number of females recorded to calve both in year $i$ and in year $j$, where $i<j$;

$j_{\max }$ the maximum calving interval, where possible values considered are $j_{\max }=4,5,6$ and 7;

$s_{j} \quad$ the probability that a female that calved in year $m$ survives to year $m+j$;

$n$ total number of years in which calvings have been recorded.

The probabilities $q_{j}$ are related to the probabilities $h_{j}$ by the following equation:

$$
q_{j}=\sum_{i=1}^{j} h_{i} q_{j-i}
$$

where $q_{0}=1$ and the $h_{i}$ satisfy the condition:

$$
\sum_{i=1}^{j_{\max }} h_{i}=1
$$

The $n_{i j}$ are assumed to follow a Poisson distribution with expected value given by:

$$
\mu_{i j}=n_{i} s_{j-i} q_{j-i} p_{j} \quad(i<j)
$$

so that the likelihood function is then given by:

$$
L\left(n_{i j} ; p_{j}, h_{i}, S\right)=\prod_{j=1}^{n} \prod_{i=0}^{j-1} \frac{e^{-\mu_{i j}} \mu_{i j}^{n_{i j}}}{n_{i j} !}
$$

where $S$ is the annual survival rate of females (assumed constant), so that $s_{j}=S^{j}$.

The mean calving interval is given by:

$$
\sum_{j=1}^{j \max } j h_{j} s_{j} / \sum_{j=1}^{j \max } h_{j} s_{j}
$$

This model also provides estimates for $p_{j}$ given by:

$$
\hat{p}_{j}=\sum_{i=0}^{j-1} n_{i j} / \sum_{i=0}^{j-1} n_{i} q_{j-i} s_{j-i}
$$

and these in turn yield estimates of the number of calvings in each year $\left(\hat{N}_{j}\right.$ where $\left.\hat{N}_{j}=n_{j} / \hat{p}_{j}\right)$. The model proposed by Payne et al. (1990) to estimate the annual rate of increase expressed as an instantaneous rate is also applied to these data. If $N_{O}$ is the number of calvings in the first year of the study, $\delta$ is the annual instantaneous growth rate, and the trend in the calving population size is modelled as:

$$
N_{j}=N_{0} e^{\delta \cdot j}
$$

then Equation (3) can be rewritten by replacing $p_{j}$ in terms of $N_{j}$ as:

$$
\mu_{i j}=n_{i} n_{j} s_{j-i} q_{j-i} e^{-\delta \cdot j} / N_{0} \quad(i<j)
$$

and the likelihood function given by Equation (4) can be maximised to give an estimate for the annual instantaneous growth rate. Confidence intervals for the parameter estimates are obtained using the likelihood profile method (Schnute and Groot, 1992).

\section{Age at first parturition}

Photographs of any previously un-photographed adults taken on a survey were compared with those of calves taken four or more years earlier. This analysis was confined to matching calves and adults that carried grey blazes (see Best, 1990a), as these animals are known to be female (Schaeff et al., 1999). Restriction of the analysis to known females allows the estimation of the juvenile survival rate in addition to the age at first parturition. In the catalogue of adult females from 1979 to 1998 there was a total of 63 such 'grey-blazed' individuals, and from 1979 to 1992 a total of 64 grey-blazed calves was photographed. A total of 31 matches was found, all for cows photographed from 1987 onwards (see Table 4). The analysis that follows makes the tacit assumption that all calves with visible grey blazes retain them. This seems plausible because while the blazes tend to darken with age, their shapes remain unchanged over time (Payne et al., 1983; Best, 1990a).

The observed ages at first parturition are subject to the same types of bias as the observed calving intervals, in that later maturing individuals will be relatively under-represented, and some first calvings will go undetected. Hence, a modelling approach has been adopted to estimate the true median age at first parturition.

Let $m_{i}$ be the number of female calves seen in year $i$, where $i=1979, \ldots, 1992$, and $t_{k}$ be the number of such females seen to first reproduce at age $k$, where $k=6, \ldots, 13$.
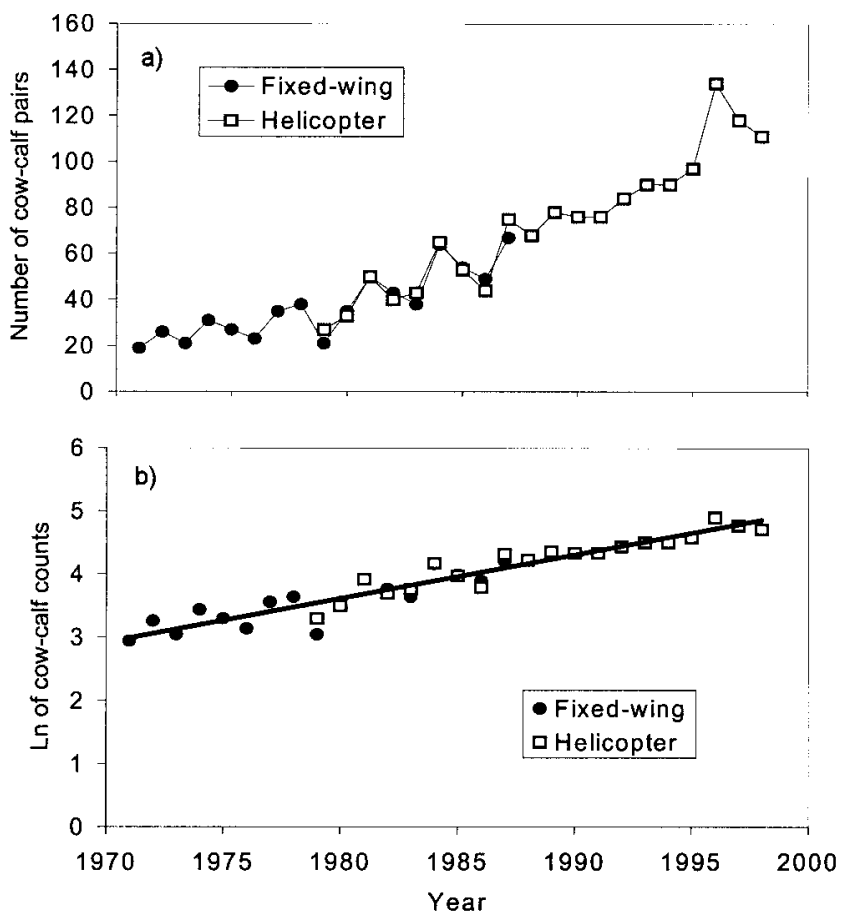

Fig. 1. Numbers of right whales with calves seen on surveys by fixed wing aircraft, 1971 to 1987 , and by helicopters 1979 to 1998 expressed as (a) raw counts, (b) natural logarithms of counts. 
Table 1

Observed right whale cow-call pairs on the south coast of South Africa between 1979 and 1998 . Number of calvings recorded in each year as well as the number of lemales that have been resighted with a call in later years are shown.

a) The number of females recorded to calve both in year $i$ and in year $j\left(n_{i j}\right)$, where $i<j$

\begin{tabular}{|c|c|c|c|c|c|c|c|c|c|c|c|c|c|c|c|c|c|c|c|}
\hline \multirow{2}{*}{$\begin{array}{l}\text { Year } i \\
(i<j)\end{array}$} & \multicolumn{19}{|c|}{ Year $j(i<j)$} \\
\hline & 1980 & 1981 & 1982 & 1983 & 1984 & 1985 & 1986 & 1987 & 1988 & 1989 & 1990 & 1991 & 1992 & 1993 & 1994 & 1995 & 1996 & 1997 & 1998 \\
\hline 1979 & 0 & 1 & 17 & 2 & 4 & 14 & 2 & 2 & 10 & 3 & 5 & 8 & 4 & 4 & 6 & 5 & 3 & 4 & 4 \\
\hline 1980 & & 0 & 0 & 22 & 2 & 2 & 15 & 4 & 3 & 17 & 5 & 3 & 15 & 3 & 3 & 15 & 6 & 3 & 10 \\
\hline 1981 & & & 0 & 2 & 31 & 0 & 4 & 27 & 3 & 5 & 15 & 8 & 6 & 12 & 5 & 4 & 16 & 6 & 5 \\
\hline 1982 & & & & 0 & 1 & 28 & 3 & 2 & 24 & 4 & 3 & 18 & 5 & 4 & 14 & 4 & 4 & 12 & 3 \\
\hline 1983 & & & & & 0 & 2 & 21 & 5 & 4 & 23 & 8 & 4 & 17 & 6 & 5 & 17 & 4 & 3 & 15 \\
\hline 1984 & & & & & & 0 & 1 & 42 & 6 & 4 & 30 & 8 & 6 & 25 & 7 & 6 & 25 & 10 & 7 \\
\hline 1985 & & & & & & & 0 & 2 & 34 & 4 & 3 & 27 & 4 & 5 & 27 & 5 & 6 & 19 & 6 \\
\hline 1986 & & & & & & & & 0 & 1 & 31 & 2 & 4 & 22 & 3 & 3 & 19 & 5 & 4 & 13 \\
\hline 1987 & & & & & & & & & 0 & 3 & 43 & 5 & 4 & 34 & 4 & 6 & 34 & 8 & 9 \\
\hline 1988 & & & & & & & & & & 0 & 1 & 37 & 3 & 4 & 34 & 5 & 7 & 28 & 4 \\
\hline 1989 & & & & & & & & & & & 0 & 2 & 47 & 7 & 4 & 38 & 8 & 10 & 31 \\
\hline 1990 & & & & & & & & & & & & 0 & 0 & 39 & 1 & 4 & 35 & 4 & 5 \\
\hline 1991 & & & & & & & & & & & & & 0 & 2 & 46 & 5 & 6 & 37 & 7 \\
\hline 1992 & & & & & & & & & & & & & & 0 & 1 & 50 & 13 & 4 & 38 \\
\hline 1993 & & & & & & & & & & & & & & & 0 & 1 & 48 & 6 & 6 \\
\hline 1994 & & & & & & & & & & & & & & & & 0 & 1 & 55 & 3 \\
\hline 1995 & & & & & & & & & & & & & & & & & 0 & 1 & 54 \\
\hline 1996 & & & & & & & & & & & & & & & & & & 0 & 3 \\
\hline 1997 & & & & & & & & & & & & & & & & & & & 0 \\
\hline
\end{tabular}

b) Number of calvings recorded in each year $i\left(n_{i}\right)$

\begin{tabular}{|c|c|c|c|c|c|c|c|c|c|c|c|c|c|c|c|c|c|c|c|c|}
\hline Ycar & 1979 & 1980 & 1981 & 1982 & 1983 & 1984 & 1985 & 1986 & 1987 & 1988 & 1989 & 1990 & 1991 & 1992 & 1993 & 1994 & 1995 & 1996 & 1997 & 1998 \\
\hline$n_{i}$ & 27 & 33 & 50 & 40 & 43 & 65 & 53 & 44 & 76 & 69 & 78 & 76 & 76 & 85 & 90 & 90 & 97 & 134 & 118 & 111 \\
\hline
\end{tabular}

Define $\lambda_{k}$ to be the proportion of animals of age $k$ which have reached first parturition (either at that age or earlier). This is re-parameterised as:

$$
\lambda_{k}= \begin{cases}1 /\left[1+e^{-\left(k-a_{m}\right) / \Lambda}\right] & k \geq 6 \\ 0 & k<6\end{cases}
$$

where $a_{m}$ is the age at which $50 \%$ of the population reach first parturition and $\Delta$ measures the spread of this ogive. Define $\tilde{S}$ as the survival rate for the first year of life ( $S$ is assumed to apply for each year thereafter); then for each $k$ the expected value of $t_{k}\left(\hat{t}_{k}\right)$ can be represented in terms of $m_{i}$, $\tilde{S}, S, p_{j}$ and $\lambda_{\mathrm{k}}$. For example, when $k=6, \hat{t}_{k}$ is given by:

$$
\hat{t}_{6}=\sum_{i} m_{i} \tilde{S} S^{5} p_{i+6} \lambda_{6}
$$

and for $k=7, \hat{t}_{k}$ is given by:

$$
\hat{t}_{7}=\sum_{i} m_{i} \tilde{S} S^{6} p_{i+7}\left(\lambda_{7}-\lambda_{6}\right)+\sum_{i} m_{i} \tilde{S} S^{6}\left(1-p_{i+6}\right) \lambda_{6} h_{1} p_{i+7}
$$

and so on for other values of $k$.

The observed $t_{k}$ are assumed to follow Poisson distributions with expected value $\hat{t}_{k}$ so that the likelihood function is given by ${ }^{1}$ :

$$
L\left(t_{k} ; a_{m}, \Delta, S, p_{j}, h_{i}, \tilde{S}, \delta, N_{0}\right)=\prod_{k=6}^{13} \frac{e^{-\hat{t}_{k}}\left(\hat{t}_{k}\right)^{t_{k}}}{t_{k} !}
$$

Incorporating the information available on matched calves and adults as well as the adult resighting information, one can obtain estimates for the calving interval and the age at first parturition concurrently. This was achieved by

\footnotetext{
${ }^{1}$ Strictly this product should be extended to values of $k>13$, for which expectations are non-zero even though there are no actual recordings. However, for the parameter values estimated, the expectation for $k=14$ is already very small (about 0.2 ), so that this complication was ignored for simplicity.
}

maximising the likelihood obtained from the product of the two individual likelihood functions given by Equations (4) and (11). Penalty functions were used to ensure that $h_{i}$ values were not negative and that the juvenile survival rate $(\tilde{S})$ did not exceed the adult survival rate $(S)$. This last constraint is imposed because it seems likely that if the mother dies during a calf's first year of life, the calf would die too.

\section{RESULTS}

\section{Counts on annual surveys}

Fig. 1a shows the counts of right whales with calves seen on fixed-wing surveys from 1971-1987, and helicopter surveys from 1979-1998. The counts for the helicopter surveys are based on the actual numbers photographed, as obtained after the photographs have been matched and any inadvertent duplicates omitted. For the period of overlap between surveys (1979-1987), correlation between counts on the two surveys is excellent $\left(r^{2}=0.914\right)$, indicating that survey efficiencies using fixed-wing and helicopter aircraft were similar. If the counts are expressed as natural logarithms and plotted against time (Fig. 1b), then annual instantaneous increase rates (i.e. $\delta$ of Equation (7)) of $0.0679(\mathrm{SE}=0.0102)$ are obtained for the fixed-wing surveys from 1971-1987, and $0.0692(\mathrm{SE}=0.0058)$ for helicopter surveys from 1979-1998. These rates of increase are not significantly different $(t=0.11$, two-tailed $p>0.90)$, and a common regression line indicates that the population has been increasing at an instantaneous rate of $0.068(\mathrm{SE}=0.004)$ per year for the last 28 years.

\section{Calving interval}

Table 1 gives the observed values for the number of right whale calvings recorded each year and the number of females that were observed to calve in both year $i$ and year $j$. Fig. 2 shows the distributions of observed calving intervals 


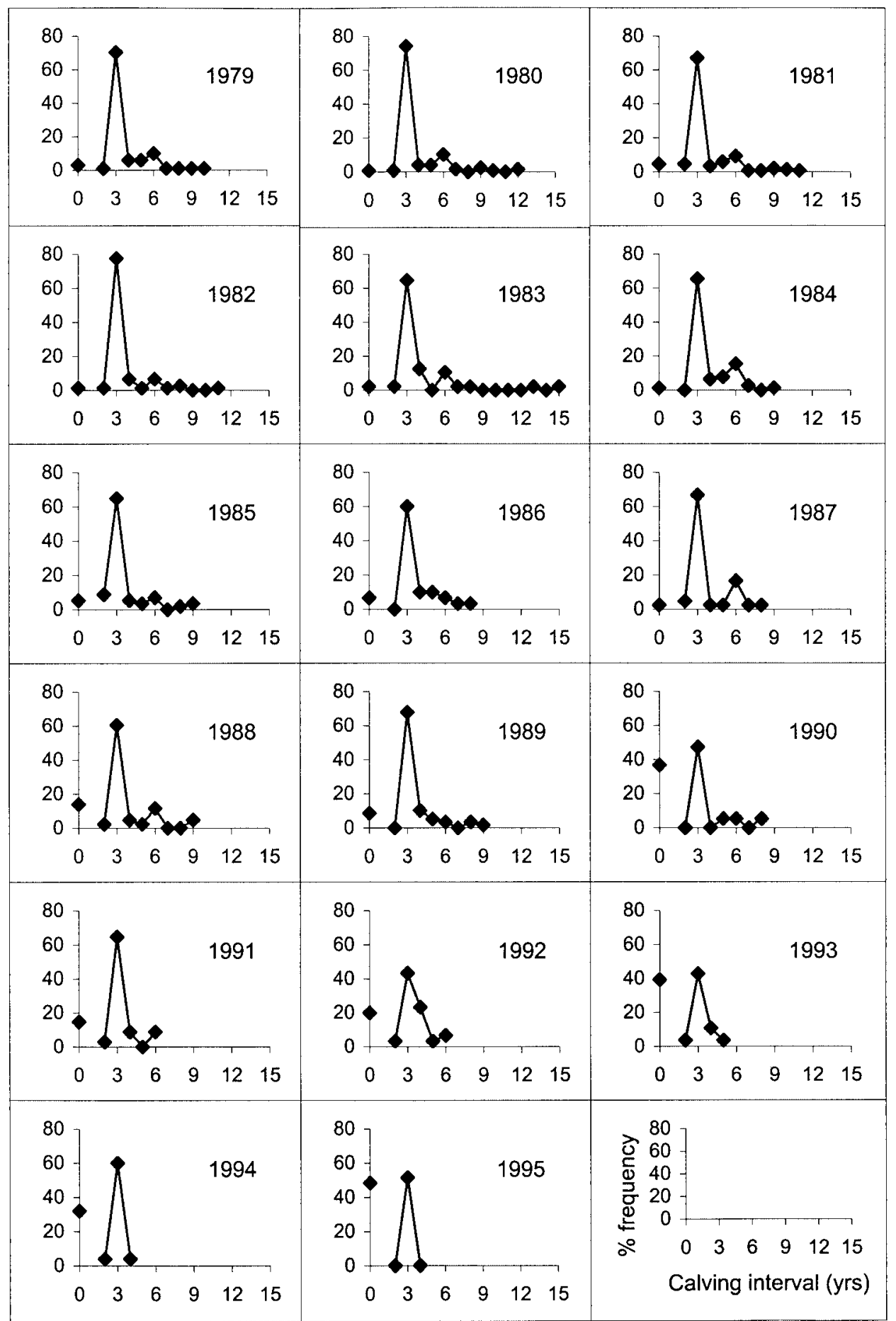

Fig. 2. The distribution of observed calving intervals by annual cohort $(>=$ incomplete calving intervals).

for each cohort of females from 1979 to 1995 (the data for the 1996 and subsequent cohorts are not included because the time for which they have been at large is only two years or less). The distribution has an obvious mode for each cohort at three years, and for most cohorts a much smaller mode around six years. Some early cohorts also have a few intervals around nine years, and very few at about 12 years: the longest observed interval is 15 years. Arithmetic means of the observed intervals range from 3.00-4.09 years, with four of the five lowest (3.00-3.57) occurring in the years 1991-1995, clearly indicating the effect of the exclusion of longer intervals due to the brief period that these animals have been 'at large'.

Table 2 gives the estimated probability distributions of calving intervals from the Payne et al. (1990) model, for different choices of the maximum calving interval $\left(j_{\max }\right)$.
The log-likelihood values, together with considerations of parsimony, indicate that the distribution with a maximum calving interval of five years produces the best fit (although a maximum value of six years is not discounted). This distribution has a mean calving interval of 3.12 years with a (likelihood-profile-based) $95 \%$ CI of $3.07,3.17$. Fig. 3 compares the distribution of observed and model predicted (Equation (3) summed over $i$ ) frequencies of subsequent calvings in relation to the period $(j-i)$ elapsed since the first sighting of an animal with a calf, on the assumption of a maximum interval of five years; the overall fit is good $\left(\chi^{2}=8.89, p=0.632\right)$.

The model also provides estimates of the probability that a calving which occurs in a particular year is recorded (Table 3 ); from this, the 'true' number of calvings occurring in that year can be estimated (Fig. 4). Recording probabilities are 
Table 2

Estimates of the probability distribution of calving intervals $\left(h_{j}\right)$, mean calving interval (yr) and annual survival rate $(S)$ for right whales off South Africa for different choices of maximum calving interval $\left(j_{m a x}\right)$, based on the Payne et al. (1990) model of Equations (1) to (4). Results in brackets represent $95 \%$ confidenee intervals obtained by the likelihood profile method.

\begin{tabular}{ccccc}
\hline & \multicolumn{4}{c}{ Assumed maximum calving interval (ycars) } \\
\cline { 2 - 5 } Parameter & 4 & 5 & 6 & 7 \\
\hline$h_{1}$ & 0.00 & 0.00 & 0.00 & 0.00 \\
$h_{2}$ & 0.05 & 0.03 & 0.02 & 0.02 \\
$h_{3}$ & 0.87 & 0.85 & 0.71 & 0.71 \\
$h_{4}$ & 0.08 & 0.08 & 0.08 & 0.08 \\
$h_{5}$ & - & 0.04 & 0.05 & 0.05 \\
$h_{6}$ & - & - & 0.14 & 0.14 \\
$h_{7}$ & - & - & - & 0.00 \\
$S$ & 0.985 & 0.983 & 0.979 & 0.979 \\
& \multicolumn{5}{c}{$(0.972,0.994)$} & 3.54 & 3.55 \\
Mean calving interval & 3.03 & 3.12 & 3,764 & \\
Log-likelihood & 3,758 & 3.764 & 3,766 & 3,766 \\
Decision & reject & accept and select & accept & reject \\
\hline
\end{tabular}

\section{Table 3}

The recorded number and expected 'true' number of calvings for the years 1979 to 1998 . The estimated probability that a calving in year $j$ is recorded is also given. The available data preclude the model providing estimates for the first three years: 1979 to 1981.

\begin{tabular}{cccc}
\hline Year $i$ & $\begin{array}{c}\text { Recorded } \\
\text { number }\end{array}$ & $\begin{array}{c}\text { Expected } \\
\text { number }\end{array}$ & $\begin{array}{c}\text { Estimated probability } \\
\text { of recording }\left(\hat{p}_{j}\right)\end{array}$ \\
\hline 1979 & 27 & - & - \\
1980 & 33 & - & - \\
1981 & 50 & - & - \\
1982 & 40 & 52 & 0.76 \\
1983 & 43 & 79 & 0.82 \\
1984 & 65 & 65 & 0.82 \\
1985 & 53 & 57 & 0.81 \\
1986 & 44 & 97 & 0.77 \\
1987 & 76 & 87 & 0.79 \\
1988 & 69 & 96 & 0.80 \\
1989 & 78 & 96 & 0.81 \\
1990 & 76 & 97 & 0.79 \\
1991 & 76 & 109 & 0.78 \\
1992 & 85 & 118 & 0.78 \\
1993 & 90 & 119 & 0.76 \\
1994 & 90 & 129 & 0.75 \\
1995 & 97 & 177 & 0.75 \\
1996 & 134 & 157 & 0.76 \\
1997 & 118 & 150 & 0.75 \\
1998 & 111 & & 0.74 \\
\hline
\end{tabular}

generally high ( $>70 \%$ ), but seem to have declined slightly in recent years.

The true number of calvings annually (provided the reproductive rate remains constant) can be used as an index of the abundance of mature females. The model of Payne et al. (1990) for estimating a trend in the number of calvings (Equations (7) and (8)) produces an instantaneous rate of increase from 1982-1998 of 0.071 per annum (Fig. 5), with a $95 \%$ CI $0.059,0.082$. This is very similar to the rate estimated from counts on the same helicopter surveys from 1979-1998 (0.0692).

\section{Incorporating age at first parturition}

Table 4 shows the number of grey-blazed female calves seen in year $i$ and the number of such females seen to calve for the first time at age $k$. These apparent ${ }^{2}$ ages at first parturition

2 The word 'apparent' is used to signify that the actual first calving of the animal might not have been detected.

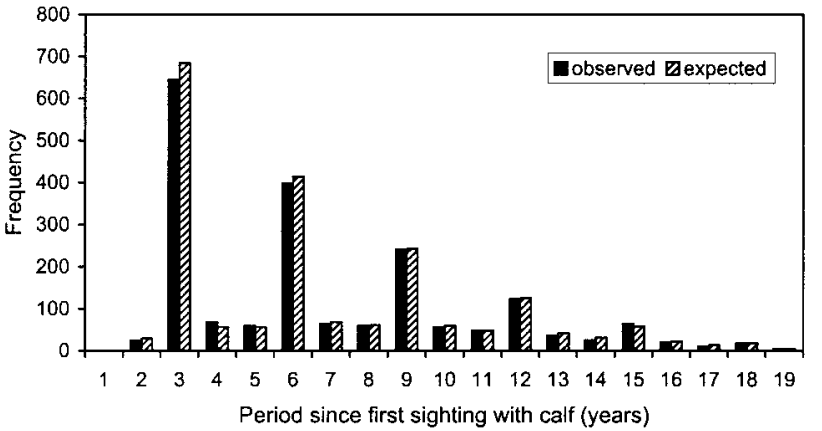

Fig. 3. The distribution of observed and expected subsequent calving intervals in relation to the period elapsed since an animal was first sighted with a calf.

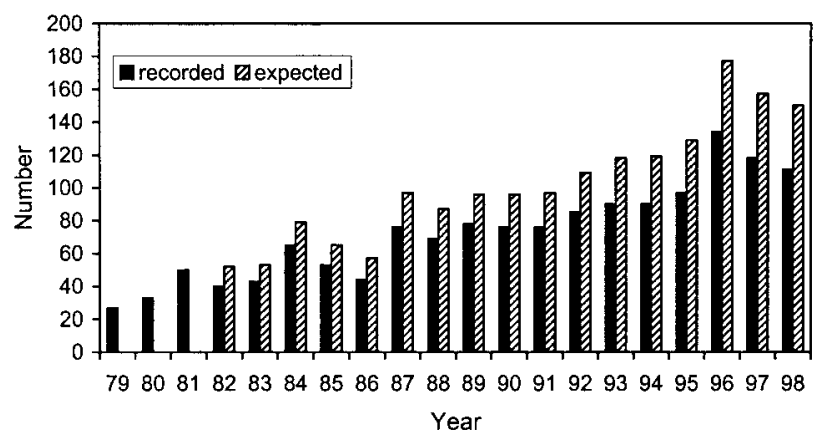

Fig. 4. The distribution of recorded number and expected 'true' number of calvings for the years 1979-1998. The available data preclude the model providing expected numbers for the first three years: 1979-1981.

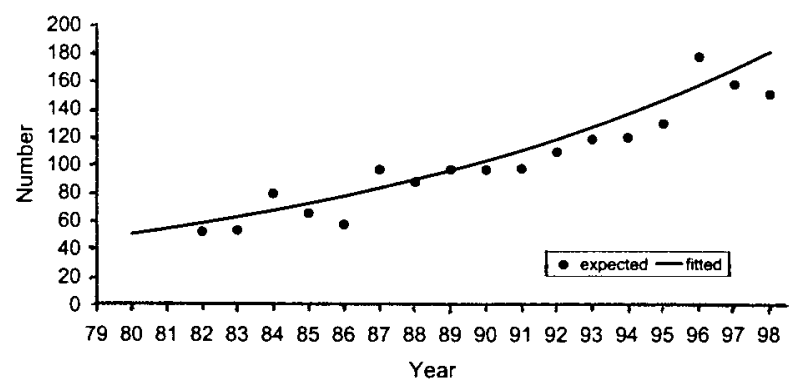

Fig. 5. Trend in the expected number (from Fig. 4) of total calvings by year off South Africa, 1982-1998. The fitted line is estimated using Equations (7) and (8).

Table 4

Observed numbers of grey-blazed right whale calves (known to be female) on the south coast of South Africa between 1979 and 1992, and the number of such females seen to first reproduce at age $k$.

(a) The number of female calves seen in year $i\left(m_{i}\right)$.

\begin{tabular}{cccccccc}
\hline Year $i$ & 1979 & 1980 & 1981 & 1982 & 1983 & 1984 & 1985 \\
\hline$m_{\mathrm{i}}$ & 3 & 3 & 5 & 1 & 2 & 4 & 10 \\
\hline Year $i$ & 1986 & 1987 & 1988 & 1989 & 1990 & 1991 & 1992 \\
\hline$m_{\mathrm{i}}$ & 1 & 5 & 2 & 5 & 6 & 7 & 10
\end{tabular}

(b) Number of female calves seen in some year $i$ that are later seen to first reproduce in year $j$ at age $k=j-i\left(t_{k}\right)$.

\begin{tabular}{ccccccccc}
\hline Age $(k)$ & 6 & 7 & 8 & 9 & 10 & 11 & 12 & 13 \\
\hline$t_{k}$ & 6 & 3 & 8 & 7 & 2 & 2 & 1 & 2 \\
\hline
\end{tabular}




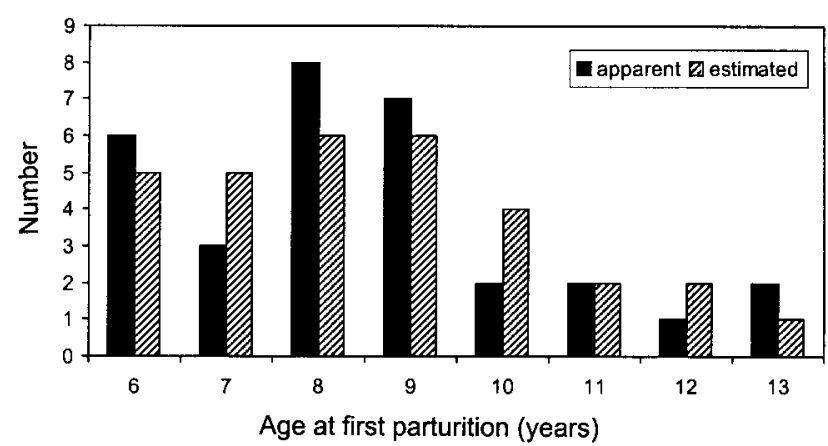

Fig. 6. The distribution of apparent and corresponding model-estimated (Equations (9) to (11)) ages at first parturition in right whales off South Africa. Note: the word 'apparent' is used because missed calvings mean that some observations above reflect subsequent rather than true first parturition.

\section{Table 5}

Estimates of various demographic parameters (see text for definitions) for right whales off South Africa for different choices of maximum calving interval based upon the model of Equations (9) to (11) which incorporates data on observations of apparent first parturition. Results in brackets represent $95 \%$ confidence intervals obtained by the bootstrap procedure of Appendix 2.

\begin{tabular}{|c|c|c|c|c|}
\hline \multirow[b]{2}{*}{ Parameter } & \multicolumn{4}{|c|}{ Assumed maximum calving interval (years) } \\
\hline & 4 & 5 & 6 & 7 \\
\hline$h_{l}$ & 0.00 & 0.00 & 0.00 & 0.00 \\
\hline$h_{2}$ & 0.05 & $\begin{array}{c}0.03 \\
(0.02,0.04)\end{array}$ & 0.03 & 0.03 \\
\hline$h_{3}$ & 0.87 & $\begin{array}{c}0.85 \\
(0.84,0.87)\end{array}$ & 0.78 & 0.78 \\
\hline$h_{4}$ & 0.08 & $\begin{array}{c}0.08 \\
(0.07,0.09)\end{array}$ & 0.08 & 0.08 \\
\hline$h_{5}$ & - & $\begin{array}{c}0.04 \\
(0.01,0.06)\end{array}$ & 0.04 & 0.04 \\
\hline$h_{6}$ & - & - & 0.07 & 0.07 \\
\hline$h_{7}$ & - & - & - & 0.00 \\
\hline$S$ & 0.987 & $\begin{array}{c}0.986 \\
(0.976,0.999)\end{array}$ & 0.986 & 0.986 \\
\hline L & 0.076 & $\begin{array}{c}0.071 \\
(0.059,0.082)\end{array}$ & 0.067 & 0.068 \\
\hline \multirow[t]{2}{*}{$N_{0}$} & 45 & $\begin{array}{c}47 \\
(40,56)\end{array}$ & 46 & 46 \\
\hline & 0.888 & $\begin{array}{c}0.913 \\
(0.601,0.994)\end{array}$ & 0.908 & 0.865 \\
\hline$a_{m}$ & 8.01 & $\begin{array}{c}7.88 \\
(7.17,9.29)\end{array}$ & 8.02 & 8.09 \\
\hline$\varnothing$ & 1.13 & $\begin{array}{c}1.03 \\
(0.60,2.09)\end{array}$ & 1.06 & 1.12 \\
\hline $\begin{array}{c}\text { Mean calving } \\
\text { interval }\end{array}$ & 3.03 & $\begin{array}{c}3.12 \\
(3.07,3.17)\end{array}$ & 3.35 & 3.33 \\
\hline Log-likelihood & 3,770 & 3,776 & 3,777 & 3,777 \\
\hline Decision & Reject & Accept & Reject & Reject \\
\hline
\end{tabular}

range from 6-13 years (mean 8.5 years, SD 2.0 years; Fig. 6). Table 5 gives the estimated parameters when the model of Payne et al. (1990) for calving intervals is updated to include information available on matched female calves and adults to estimate the age at first parturition and improve survival rate estimates. Percentile bootstrap confidence intervals (Efron, 1981; 1982) are given for the parameter estimates ${ }^{3}$. The log-likelihood values indicate that a maximum calving interval of 5 years should be chosen. The point estimates for the probabilities of different calving intervals do not change

\footnotetext{
3 Likelihood-profile-based confidence interval estimates were also computed for a number of the quantities estimated; the results were near identical to those obtained from this bootstrap approach.
}

from those obtained from the Payne et al. (1990) model in isolation (Table 2). Fig. 6 also shows the distribution of apparent age at first parturition predicted by the model of Equation (9) to (11). The overall fit to the observed distribution is $\operatorname{good}\left(\chi^{2}=4.13, p=0.127\right)$.

From the first parturition ogive fitted by the model (Fig. 7), the age at which $50 \%$ of females have their first calf is estimated as 7.88 years (95\% CI 7.17, 9.29).

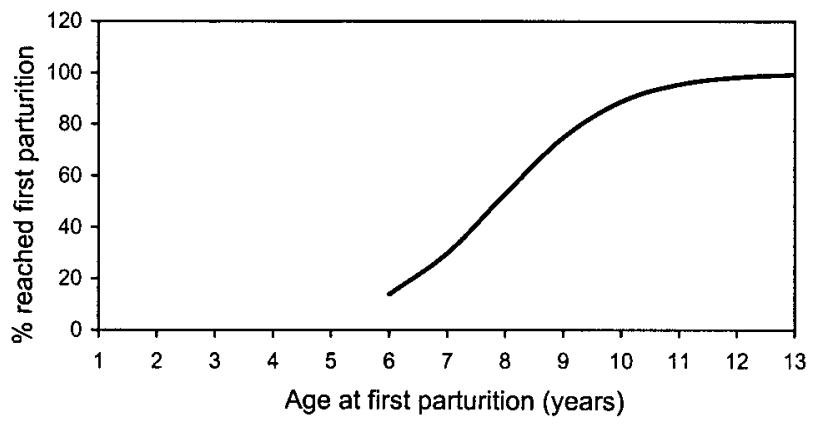

Fig. 7. Ogive of estimated proportion of females at each age that have calved at least once.

\section{Survival rates}

The model used for estimating calving intervals can also produce estimates of adult female survival rate. The best estimate for the South African right whale data is $0.983(95 \%$ CI $0.972,0.994)$ when the model proposed by Payne et al. (1990) is applied. This estimate increases to 0.986 (95\% CI $0.976,0.999$ ) when the combined model of Equations (9) to (11) is used.

There is also the potential for estimating the juvenile survival mortality rate, given the restriction of the reproduction data used (Table 4) to animals known to be female. This results in a juvenile (to age 1) survival rate estimate of 0.913 (95\% CI $0.601,0.994)$.

\section{DISCUSSION}

The average calving interval in South African right whales was estimated previously as $3.18(\mathrm{SE}=0.09)$ years (Best, 1990a). This estimate included an attempted correction for missed calving intervals by stratifying the data to exclude animals calving on the periphery of the survey area, but did not specifically incorporate resighting probabilities. As such, it is less reliable than the estimate made in this paper (3.12 years, 95\% CI 3.07, 3.17).

The adult female mortality rate in South African right whales was also estimated previously as 0.0227-0.0260 (equivalent to a survival rate of 0.974-0.977), although this estimate assumed that detection (= sighting) probability had remained constant at around $77 \%$ (Best and Kishino, 1998). Estimates in Table 3 suggest that the probability of recording calvings has actually declined slightly over the time period (from about 0.80 in 1982-4 to 0.75 in 1996-8); such a decline would have effectively caused the mortality rate in Best and Kishino (1998) to be over-estimated. Hence the survival rate estimate produced in this paper is likely to be more reliable $(0.986,95 \%$ CI 0.976 , 0.999).

Juvenile survival (to age 1) was estimated as 0.88 in North Atlantic right whales (Kraus, 1990). This figure excluded neonatal mortality, estimated as 0.05 by Kraus (1990). Best 
et al. (2001) document mortalities of 31 'calves of the year' in South African right whales between 1963 and 1998. Thirty of these calves were recorded between 1969 and 1998, during which time a total of 1,701 calves was counted on annual surveys. As $86 \%$ of observed neonatal mortality occurred prior to the timing of the annual surveys (Best et al., 2001 ), the neonatal mortality rate would amount to $30 \times$ $0.86 / 1,701=0.015$. This estimate makes no allowance for missed calvings, but neither does it attempt to estimate missed mortalities, so the direction of any likely bias is unknown. This neonatal mortality is additional to the juvenile mortality of 0.087 estimated from the photo-identification data; in effect, it may be 'hidden' in the model, either as a greater age at first parturition or an extended mean calving interval. Given that the majority of stranded calves are believed to be the offspring of primiparous females (Best and Rüther, 1992), the former is the more probable.

The process of comparing photographs from the different surveys to establish 'synonyms' has the potential to produce both false positives and false negatives. The latter, which can arise as a result of minor changes in callosity patterns or of poor quality photographs, are considered to be relatively more likely than the former, and would lead to negatively biased estimates of the adult female survival rate. However, given the very low number of cases subsequently identified as false negatives when photographs from later surveys became available, any such bias is probably small.

In an earlier analysis of biological and other data from this population, Butterworth and Best (1990) concluded that the observed rate of increase was compatible only with a fairly small region of 'biologically realistic' parameter space. Given an annual reproductive rate of 0.314 , the best estimate of annual instantaneous increase rate at that time (0.068) could be generated only if the age at first parturition was between seven and nine years and the adult female mortality rate between 0.01 and 0.02 , unless the population was open to immigration (the lower limit of each of these two sets of bounds was based upon argued biological realism and observations off Argentina in Payne et al., 1990). As concluded by Butterworth and Best (1990), a powerful way to test whether the observed increase rate contained an element of immigration would be to obtain estimates of the age at first parturition (and possibly adult mortality rate) from longitudinal studies of individually identified animals: if these estimates should lie outside the feasible region of parameter space, it could be concluded that immigration was occurring.

The new or updated estimates for mean calving interval, age at first parturition and adult (plus juvenile) survival rate obtained in this paper now provide the opportunity to test their compatibility with observed population increase rates. Using the 'balance equation' for a growing population with a steady age structure (Butterworth and Best, 1990):

$$
(1+r)^{a_{n t}}=(1+r)^{a_{n}-1} S+q \rho \tilde{S} S^{a_{n t}-1}
$$

where:

$r$ is the annual rate of population increase;

$q$ is the proportion of births that are female; and

$\rho$ is the calving rate,

the parameter $r$ can be calculated. It is assumed that the proportion of births that are female is 0.5 (Tormosov et al., 1998). The calving rate is larger than the reciprocal of the mean calving interval because an adult whale has a calf immediately it enters the breeding population, as pointed out by Cooke et al. (1993). The method to compute the calving rate is given in Appendix 1. From Equation (12), the distribution of $r$ can be computed using bootstrap methods (Appendix 2). Fig. 8 gives the distribution of $r$ computed from biological parameters using Equation (12) and that obtained from the estimate of annual instantaneous growth rate parameter $\delta$ of Equation (7) (i.e. solving for $r$ in the equation $\left.1+r=e^{\delta}\right)$. Since these distributions reflect near complete overlap, there is no indication that immigration is needed to account for the annual instantaneous growth rate of 0.071 .

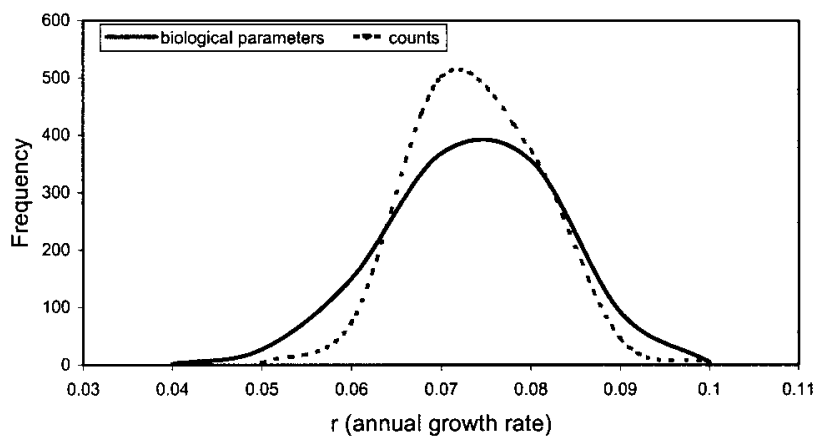

Fig. 8. Comparison of distributions of annual growth rate $(r)$ computed from biological parameters (Equation (12)) and estimated directly from annual calvings (Equation (7)).

\section{ACKNOWLEDGEMENTS}

We are indebted to a number of people who have unselfishly acted as assistants in the aerial surveys: these include Michael Meÿer, Keiko Sekiguchi, Penny Meÿer, Desray Reeb, Ken Findlay, John Bassett, Marc Sanson, Kevin Smith, Colin Potts, Robin Weekes, Robin Horne, Graham Ross, Peter Shaughnessy, Norman Denton, Vic Cockcroft, David Cram, Chris Boltman, Maggi Best, Hennie Crous and Anka von Loewensprung. The skill of pilots Sid Rowe, Bob Matthews, Mike Tilson, Tim Pryor, Jerry Broberg, Mike Franz, Dick Richards, Keith Hall, Peter Savage, Doug Notten, John Lawson, Clive Bartmann, Bernard Freylink, Brent Curtin, Gary Wilson, George Wrigley, Mike Fagan, Ken Whittal, Bill Walzer and Stan Botha was essential to the success of the surveys. Funding for the survey programme was provided by the South African Department of Environment Affairs and Tourism (and its predecessors), the South African Scientific Committee for Antarctic Research, the South African Marine Corporation Ltd, the World Wide Fund for Nature (South Africa), Exclusive Touch Pty Ltd, Southern Right Cellars and Moby Dick Rum. PBB and AB acknowledge the support of the National Research Foundation (Foundation for Research Development) and the National Antarctic Programme, South Africa. The surveys were conducted under a series of permits issued to PBB in terms of the Sea Fisheries Act (Act 58 of 1973), Sea Fishery Act (Act 12 of 1988) and the Marine Living Resources Act (Act 18 of 1998). We thank Lex Hiby and an anonymous reviewer for their comments on an earlier version of this paper, and Justin Cooke for pointing out a simple method to derive the result in Appendix 1. 


\section{REFERENCES}

Best, P.B. 1990a. Natural markings and their use in determining calving intervals in right whales off South Africa. S. Afr. J. Zool. 25(2):114-23.

Best, P.B. 1990b. Trends in the inshore right whale population off South Africa, 1969-1987. Mar. Mammal Sci. 6(2):93-108.

Best, P.B. and Kishino, H. 1998. Estimating natural mortality rate in reproductively active female southern right whales, Eubalaena australis. Mar. Mammal Sci. 14(4):738-49.

Best, P.B. and Rüther, H. 1992. Aerial photogrammetry of southern right whales, Eubalaena australis. J. Zool., London. 228:595-614.

Best, P.B., Peddemors, V.M., Cockcroft, V.G. and Rice, N. 2001. Mortalities of right whales and related anthropogenic factors in South African waters, 1963-1998. J. Cetacean Res. Manage. (special issue) 2:171-176.

Butterworth, D.S. and Best, P.B. 1990. Implications of the recovery rate of the South African right whale population for baleen whale population dynamics. Rep. int. Whal. Commn 40:433-47.

Cooke, J.G., Payne, R. and Rowntree, V. 1993. Updated estimates of demographic parameters for the right whales (Eubalaena australis) observed off Peninsula Valdes, Argentina. Paper SC/45/O24 presented to the IWC Scientific Committee, April 1993 (unpublished). 8pp.

Efron, B. 1981. Nonparametric standard errors and confidence intervals (with discussion). Can. J. Stat. 9:139-72.
Efron, B. 1982. The Jacknife, the Bootstrap, and other resampling plans. Soc. Ind. Appl. Math., Monogr., No. 38. Arrowsmith Ltd, Bristol, England. 92pp.

Kraus, S.D. 1990. Rates and potential causes of mortality in North Atlantic right whales (Eubalaena glacialis). Mar. Mammal Sci. 6(4):278-91.

Payne, R., Brazier, O., Dorsey, E.M., Perkins, J.S., Rowntree, V.J. and Titus, A. 1983. External features in southern right whales (Eubalaena australis) and their use in identifying individuals. pp. 371-445. In: R. Payne (ed.) Communication and Behavior of Whales. AAAS Selected Symposia Series 76. Westview Press, Colorado. xii+643pp.

Payne, R., Rowntree, V., Perkins, J.S., Cooke, J.G. and Lankester, K. 1990. Population size, trends and reproductive parameters of right whales (Eubalaena australis) off Peninsula Valdes, Argentina. Rep. int. Whal. Commn (special issue) 12:271-8.

Schaeff, C.M., Best, P.B., Rowntree, V.J., Payne, R., Jarvis, C. and Portway, V.A. 1999. Dorsal skin color patterns among southern right whales (Eubalaena australis): Genetic basis and evolutionary significance. J. Hered. 94(4):464-71.

Schnute, J.T. and Groot, K. 1992. Statistical analysis of animal orientation data. Anim. Behav. 43:15-33.

Tormosov, D.D., Mikhalev, Y.A., Best, P.B., Zemsky, V.A., Sekiguchi, K. and Brownell Jr, R.L. 1998. Soviet catches of southern right whales, Eubalaena australis, 1951-1971; biological data and conservation implications. Biol. Conserv. 86:185-97.

\section{Appendix 1}

\section{COMPUTING PREGNANCY RATE}

Assume that adult natural survival rate is $S$ and that the population is increasing at a steady annual rate, $e^{\delta}$. Set $z=S e^{-\delta}$. Then if $a_{m}$ is the age at first parturition (assumed to be fixed) and there are $N_{0}$ females of this age at present, the total number of adult females in the population is:

$$
N_{\text {tot }}=N_{0}+N_{0} z+N_{0} z^{2}+\cdots=\frac{N_{0}}{(1-z)}
$$

since $S<1$ and $\delta>0$ so that $z<1$.

Note that the proportions-at-age in this population are identical to those of a population in equilibrium with annual survival rate of $z$. Thus, the numbers of calves produced annually at present is equal to the number of calves produced by a single cohort of such a population over its lifespan.

Let $O_{k}$ be the number of calves produced that are the $k$ th offspring of their respective mothers. From the assumption of a fixed age at first parturition, the number of first offspring is:

$$
O_{1}=N_{0}
$$

The number of second offspring is made up as:

$\mathrm{O}_{2}=$ Proportion of $N_{0}$ females which survive one year and then reproduce +

Proportion of $N_{0}$ females which survive two years and reproduce for the first time since producing their offspring $+\ldots$

$$
\begin{aligned}
& =N_{0} z h_{1}+\mathrm{N}_{0} z^{2} h_{2}+\ldots \\
& =N_{0} \sum_{j=1}^{j_{\max }} z^{j} h_{j}
\end{aligned}
$$

Now since calving and survival probabilities are assumed to be independent, the proportion $(w)$ of the $N_{0}$ whales that survive to produce their second offspring is the same as the proportion of those which produce a second offspring that survive to produce their third, and so on, i.e.:

$$
O_{k+1} w O_{k}
$$

where from (A1.3):

$$
w=\sum_{j=1}^{j_{\max }} z^{j} h_{j}
$$

where $w<1$ as $z<1$ and $h_{j} \leq 1$, so that:

$$
O_{k}=\left[\sum_{j=1}^{j_{\max }} z^{j} h_{j}\right]^{k} O_{1}
$$

Now the total number of calves born is the sum of those that are their mothers' first, second, third...offspring, i.e.:

$$
\begin{gathered}
O_{\text {tot }}=O_{1}+O_{2}+O_{3}+\cdots \\
=\sum_{k=0}^{\infty} O_{1}\left[\sum_{j=1}^{j_{\max }} z^{j} h_{j}\right]^{k} \\
=\frac{N_{0}}{\left\{1-\sum_{j=1}^{j_{\max }} z^{j} h_{j}\right\}}\left(\text { as } w=\sum_{j=1}^{j_{\max }} z^{j} h_{j}<1\right)
\end{gathered}
$$

Thus, the calving rate $\rho$ is given by:

$$
\begin{gathered}
\rho=\frac{\text { number of births }}{\text { number of adult females }}=\frac{O_{t o t}}{N_{t o t}} \\
=\frac{(1-z)}{\left\{1-\sum_{j=1}^{j_{\max }} z^{j} h_{j}\right\}}
\end{gathered}
$$




\section{Appendix 2}

\section{COMPUTATION OF THE PARAMETRIC BOOTSTRAP DISTRIBUTION OF $r$ AND OTHER DEMOGRAPHIC PARAMETERS}

The following algorithm was used to estimate the distribution of the annual growth rate $(r)$ (the same procedure also yields the distributions for other parameters).

(1) The number of calvings recorded in year $i\left(n_{i}\right)$ and the number of female calves seen in year $j\left(m_{j}\right)$ are assumed to be known and taken to be the number observed.

(2) The number of females recorded to calve both in year $i$ and in year $j$, where $i<j\left(n_{i j}\right)$ are generated as a Poisson random variable with expected value given by Equation (3).

(3) The number of female calves seen in year $j$ that are seen to first reproduce at age $k$, where $k=6, \ldots, 13\left(t_{k}\right)$ are generated as a Poisson random variable with expected value given by equations such as Equations (9a) and (9b).

(4) The bootstrap sample consists of the observed samples $n_{i}$ and $m_{j}$ together with the generated Poisson samples $n_{i j}^{*}$ and $t_{k}^{*}$.
(5) Calculate the bootstrap replication $L^{*}\left(n_{i j}^{*}, t_{k}^{*} ; \delta^{*}, N_{0}^{*}, h_{i}^{*}\right.$, $\left.S^{*}, a_{m}^{*}, \Delta^{*}, \tilde{S}^{*}\right)$, i.e. maximise the combined likelihood function to obtain model parameter estimates using the bootstrap sample.

(6) Calculate the bootstrap replication $r^{*}$, the annual growth rate of the above bootstrap replication, using Equation (12).

(7) Repeat steps 1-6 $B$ times (where $B$ is in the range of 500-1,000), obtaining $B$ independent realisations of $r^{*}$, say $r^{*}(b), b=1,2, \ldots B$.

Note: The residuals of the fit of the original models to the data were checked for consistency with the Poisson distributions assumed, with no significant evidence of either over- or under-dispersion forthcoming, so that the procedures of steps 2 and 3 above would seem defensible. 